\title{
DESAFIOS DOS ALUNOS DECLASSES MENOS FAVORECIDAS PARA INGRESSAR E PERMANECER NA UNIVERSIDADE
}

\author{
Luzia da Glória Soares ${ }^{1}$
}

\section{RESUMO}

Vive-se um momento em que cresce mundialmente o conceito de responsabilidade social como ferramenta de gestão empresarial. Vários setores da economia abandonam a visão paternalista de ação social e integram em seus planejamentos estratégicos ações socialmente responsáveis, que unem empresa e comunidade na busca de soluções para seus problemas, sejam eles locais ou globais. Dentro desse panorama, percebe-se a necessidade dos jovens cursarem o ensino superior. O presente artigo busca demonstrar os desafios dos alunos de baixa renda e de escola pública para ingressar e permanecer na universidade, partindo da constatação das dificuldades e perspectivas desses estudantes de classe menos favorecidas que almejam um futuro promissor. Apresenta também, o desinquietar da vida universitária e as necessidades desses alunos em desenvolver no âmbito social a importância do conhecimento e da aprendizagem para facilitar sua tomada de decisão rumo a um curso superior. Levando em consideração o dinamismo das entidades com os discentes e as decisões políticas administrativas que tem a possibilidade de arcar com o Auxílio destinado apoiar a permanência dos estudantes de baixa renda na Universidade.

\footnotetext{
${ }^{1}$ Licenciada em Pedagogia com Habilitação em Magistério para as Classes de Alfabetização pela Universidade do Estado da Bahia (UNEB), em Biologia pela Faculdade Integrada da Grande Fortaleza (FGF). Especializada em: Didática e Metodologia do Ensino Superior pela Faculdade de Guanambi (FG) e em Ciências Biológicas pela Faculdade Cidade de Guanhães, Minas Gerais. Professora do $6^{\circ}$ ao $9^{\circ}$ ano do Ensino Fundamental do Colégio Municipal Prefeito Francisco Teixeira Cotrim, de Pindaí - Bahia. E-mail: glorinhasoares12@hotmail.com
} 
Palavras-chave: Auxilio a Permanência. Desafios. Estudante de baixa renda. Universidade.

\title{
CHALLENGES OF THE UNDERPRIVILEGED CLASSES OF STUDENTS TO COME AND STAY AT THE UNIVERSITY
}

\begin{abstract}
We are living a moment when the world grows the concept of social responsibility as a business management tool. Several sectors of the economy drop the paternalistic view of social action and integrate into their strategic planning socially responsible actions, uniting business and community in seeking solutions to their problems, whether local or global. Within this panorama, we realize the need of the young route the higher education. This article seeks to demonstrate the challenges of low-income and public school students to enter and remain in the university, based on the identification of the difficulties and perspectives of these underprivileged class students that aims to a promising future. It also presents the disquieting of university life and the needs of students in developing the social sphere the importance of knowledge and learning to facilitate your decision making towards a degree. Taking into account the dynamics of entities with the students and the administrative policy decisions that have the ability to afford the Aid support the permanence of low-income students at the University.
\end{abstract}

Keywords: Assistance to permanence. Challenges. Low-income students. University.

\section{Introdução}

Desde os primórdios, a história da Educação Brasileira foi assinalada com a chegada dos padres da Companhia de Jesus em nossas terras, no século XVI. E com o passar dos tempos, suas atividades pedagógicas que eram uma tarefa educativa voltada para a catequese e instrução dos indígenas. Assim, à elite colonial, era oferecido outro tipo de educação, e o que pretendiam concluir seus estudos, se deslocavam para outros países. Essas ideias pedagógicas se intensificaram e adentraram aos séculos seguintes. Dessa forma são encontrados sinais dessa Pedagogia até os dias atuais. Com o surgimento do movimento 
pedagógico, conhecido por Escola Nova, que começou a delinear-se no último quartel do século XIX, opondo-se frontalmente à Escola que apelidaram de Tradicional, caracterizada, sobretudo por um conjunto de processos educativos introduzidos na escola, nomeadamente a partir do século XVII, tornou-se especialmente explícito um conflito de contornos bem definidos entre dois modelos pedagógicos. Dessa maneira, em um contexto, o aluno é comparado a um objeto a formar por uma ação exterior a exercer sobre ele, por referência a valores, normas e ideais, em outro, o educando tem consigo os meios necessários para ser sujeito da sua formação.

Conforme Faria Filho (2000), a partir da Independência do Brasil surgiram várias iniciativas para legislar a educação, com destaque a Constituição de 1824 que instituía pela primeira vez a gratuidade do ensino para todos os cidadãos, a leide 15 de novembro de 1827 determinando a criação de escolas de primeiras letras em todas as cidades, vilas e lugarejos, o Ato Adicional de 1834 e a lei de 1837 em que ambos tiveram o propósito de normatizar a instrução pública. A partir das novas discussões sobre a "forma de se ensinar", necessidade de uso de materiais didático-pedagógicos, espaço adequado para a instrução e formação adequada dos professores, é que vão surgindo novas interpretações e parâmetros necessários para a escolarização da população. E assim foi oficializada a instrução pública, no século XIX, que o elemento aluno, professor, material didático e um ambiente adequado tinham a finalidade de garantir que o ensino se efetivasse. Com essa ideia, a escola pública assumiu declaradamente, o papel de instruir para civilizar, esse inspirado no princípio de que, somente pela via da instrução, a população chegaria à civilização, porta que conduziria a nação ao progresso.

Brandão e Mendonça (1997) afirmam que no Brasil, durante os anos de 1950/1960, a mobilização em torno da modernização do país, para uns, e, para outros. A superação da situação de dependência econômica e a busca de emancipação social orientaram um conjunto de ações no âmbito do debate intelectual e da formulação de projetos de 
reorientação das políticas de Estado, que visavam a articulação entreind ustrialização,desenvolvimento científico e renovação educacional.

Com o interesse de renovar, o Brasil chega à década de 1960 com grande demanda de mão de obra especializada como reflexo de processos de crescimento industrial e econômico. Nesse sentido, havia a necessidadede mudanças urgentes na educação, sob pena de que o futuro do ensino e do país estivesse sobremaneira comprometido.

Nesse contexto, com objetivo de progresso, foi planejado um modelo de educação para o país, e neste viés, o papel dos cursos superiores era de absoluta importância. E assim, especialistas começaram a pensar e rever, os caminhos da educação brasileira. De fato, a Universidade, que sempre abre as portas para mudanças positivas e se encontra no ápice de todas as instituições educativas, está destinada, nas sociedades modernas, a desenvolver um papel cada vez mais importante na formação da sociedade para solucionar questões científicas, morais, intelectuais, políticas e econômicas de uma nação. Dessa forma, buscase, neste trabalho, compreender os desafios enfrentados por estudantes oriundos de classes menos favorecidas para ingressar e permanecer no ensino superior.

\section{A demanda dos alunos de baixa renda para ingressar na universidade}

Com a demanda de crescimento da década de 1960, a necessidade acarreta a procura crescente por cursos de formação superior que por sua vez, não acompanhavam o ritmo de evolução vivenciado pelo país. Com um processo de expansão acanhado, reflexo principalmente de políticas educacionais que vinham diminuindo os recursos para o setor, o ensino superior, ainda basicamente nas mãos do Estado, não consegue absorver esta demanda instaurada. Por essa razão, a expansão desse ensino no Brasil ficou grande parte, nas mãos da iniciativa privada. Sem a devida atenção do Estado, que em muitos momentos, fugia o controle dos mecanismos responsáveis pela qualidade da educação que era ministrada no Brasil. 
Santos (1998, p. 251) apresenta três momentos típicos no acesso a esse nível de ensino. Um primeiro, que se estendeu do século XVI ao início do XIX, denominado uma "seleção entre muito poucos", foi um período restrito à aristocracia brasileira, no qual os filhos da classe dominante eram enviados à metrópole portuguesa onde lá desenvolviam seus estudos. Um segundo momento, chamado de "seleção entre poucos", remete à vinda da família real portuguesa para o Brasil (1808) e perdurou até meados do século XX. Nessa fase, ainda que houvesse a entrada de alguns indivíduos das camadas médias, manteve-se o perfil elitista da etapa anterior. Por fim, o terceiro momento relativo ao ingresso no ensino superior, onde éencontrada uma "seleção entre muitos".

Prosseguindo aos anos 90, século XX, ocorreram processos concomitantes de quase universalização da educação fundamental, bem como uma acentuada expansão do ensino médio. Com isso, aproximase do período mais atual da demanda por vagas no ensino superior, em que ganha proeminência a reivindicação de setores da "classe média baixa" e de baixa renda.

Conforme aponta Moehlecke (2004, p. 42), a ampliação dos níveis anteriores (ensino fundamental e Médio), acabou por trazer à cena nova exigência por vagas, agora no ensino superior, e especialmente nas instituições públicas. A demanda parte de um novo estrato social, que cursou majoritariamente a escola pública e que em geral não teria as mesmas facilidades da classe média em financiar seus estudos superiores. Assim, em meio à falta de oportunidades, surgiram entre os estudantes movimentos sociais reivindicando melhorias no acesso ao ensino superior, como o fenômeno dos cursos pré-vestibulares alternativos, de baixo custo e voltados para alunos carentes e/ou negros; as ações pela gratuidade nas taxas de inscrição dos vestibulares; o movimento dos Sem-Universidade; o retorno da discussão sobre a universidade popular; as propostas pelo fim do vestibular; e as políticas de ação afirmativa por meio de cotas sociais e raciais. Numa conjuntura de expansão, muitas dessas medidas alcançaram legitimidade política e ganharam força no debate sobre democratização no final dos anos 90 . 
Gouveia (1968) já manifestava a compreensão dos limites inerentes à extensão das oportunidades educacionais para as parcelas mais desprovidas de recursos culturais e econômicos.

O limite teórico de tal democratização seria a completa equidade nas oportunidades de acesso aos diferentes níveis e tipos de ensino, oferecidos aos vários grupos da população [...]. Não se terá conseguido tal democratização mesmo quando as camadas menos favorecidas frequentar cursos superiores, enquanto os filhos de industriais se concentrarem em faculdades de Medicina, Arquitetura e Engenharia, e os filhos de operários, em cursos de economia e direito de segunda categoria (GOUVEIA, 1968, p. 233-244).

Entretanto, mesmo sabendo que a autora pensa em termos ideais, sabe-se da vivência numa sociedade que tem como traço básico a produção de desigualdades nas suas várias instâncias reduzindo, cada vez mais, a possibilidade da equidade global. Trata-se do fato de que quando as camadas menos privilegiadas, na sua luta pela conquista do acesso, conseguem atingir o nível superior, elas ficam alocadas nos cursos menos prestigiados e, portanto, naqueles que levarão à baixa remuneração e reconhecimento social.

$\mathrm{Na}$ tentativa de expandir o Ensino Superior, o Governo Federal propôs uma Reforma Universitária, cujo aspecto mais polêmico é a possibilidade de concessão de bolsas de estudos para alunos de baixa renda estudar em universidades particulares. Coube ao Estado, neste sentido, buscar as suas políticas educacionais, e adotarem planos e o ensino superior ser prioritário no país. Assim, foi dado início ao planejamento e a expansão dos cursos superiores, quer daqueles mantidos pelo Estado, ou daqueles que são resultado na iniciativa privada, e da educação nacional como um todo.

Diante disso, e dentre os planejamentos do governo em 1998, o Ministério da Educação apresentou uma proposta de reformulação do ensino, o Exame Nacional do Ensino Médio (ENEM), com o objetivo de avaliar o desempenho do estudante ao fim da escolaridade básica. 
O Enem é utilizado como critério de seleção para os estudantes que pretendem concorrer a uma bolsa no Programa Universidade para Todos (ProUni). A partir de 2009, passou a ser utilizado também como mecanismo de seleção para o ingresso no ensino superior. Foram implementadas mudanças no Exame que contribuem para a democratização das oportunidades de acesso às vagas oferecidas por Instituições Federais de Ensino Superior (IFES). Respeitando a autonomia das universidades, a utilização dos resultados do Enem para acesso ao ensino superior pode ocorrer como fase única de seleção ou combinado com seus processos seletivos próprios.

A necessidade da avaliação do sistema de ensino é uma constante ao longo da história do ensino institucionalizado como temos hoje nas escolas. Foi com a função de atender a esta demanda de mensurar o sucesso do ensino brasileiro que o ENEM foi criado. Exatamente por conta deste histórico que o ENEM passou a ser considerado como parte importante da medida para a entrada em faculdades e universidades em todo o país, já que o critério para ter acesso ao ensino superior é conseguir fazer uma boa articulação dos conhecimentos desenvolvidos durante o ensino médio.

Dessa forma, com o projeto de padronização de horizontalização da entrada na Universidade por intermédio do Sistema de Seleção Unificada (SISU) não haveria melhor recurso do que o uso do ENEM como forma de inscrição neste processo. O ENEM assumiu o papel que tem hoje em nossa sociedade, de principal ferramenta para a entrada no ensino superior a nível nacional. Observa-se que nos últimos anos tem aumentado o acesso de estudantes oriundos de escolas públicas nas universidades brasileiras, impulsionado pelo crescimento de vagas criadas por algumas iniciativas governamentais (MORCHE; NEVES, 2011). Atualmente pode-se dizer que o espaço universitário no Brasil encontra-se aberto às camadas ditas menos favorecidas, carentes e pobres e o processo de democratização da educação superior no País, em que novos meios de diferenciação acabaram produzindo novas vagas no interior do sistema de ensino universitário brasileiro. 


\section{Os jovens das camadas populares e a sua permanência na universidade}

A vida universitária de indivíduos provenientes das camadas populares constitui algo relativamente bem recente em termos históricos no Brasil. E nesse sentido, observa-se que passar no vestibular em uma universidade pode dar a sensação de missão cumprida para muitos estudantes. Porém, para grande parte dos alunos de baixa renda, conquistar uma vaga na universidade é apenas o primeiro passo, o maior problema desses estudantes, não está na aprendizagem, mas na dificuldade de se manter na faculdade com os gastos que surgem logo ao iniciar a carreira universitária, sendo necessário que eles pratiquem outras atividades para arcar com gastos que surgem como compras de livros, transporte, alimentação e também moradia. Pois a oferta do governo em prol desses custos ainda é insuficiente para atender as necessidades destes estudantes. O caminho de dificuldade trilhado, muitas vezes, impede sua permanência na escola e dificulta a moradia na cidade onde se inscreveu para o ProUni ou SISU. Por esse motivo, acontecem reprovações contínuas e gera alto índice de evasão,em razão de não conseguir custear suas despesas ao local destinado aos seus estudos.

Segundo a reportagem do Jornal do Commercio (28/08/2012) sobre as cotas nas universidades federais, engana-se quem pensa que a luta de um aluno proveniente de escola pública acaba quando ele consegue, enfim, uma vaga na universidade. Após a aprovação no vestibular, começa outra árdua batalha. Os bolsistas do ProUni têm prioridade no Fundo de Financiamento ao Estudante do Ensino Superior (FIES) do MEC, um convênio firmado com a Caixa Econômica Federal (CEF) para oferta de estágio entre beneficiados pelo programa. No entanto, a concessão de auxílios ainda é limitada, muitos estudantes recorrem a parentes e amigos para cobrir gastos com moradia e material. "Só a vaga não é condição para que alguém possa estudar, muitos alunos do programa vêm do interior e não têm a sorte de contar com a ajuda 
de parentes", diz um bolsista de 21 anos, natural de Abaetetuba, Pará. Para ele, a ajuda de custo a todos os bolsistas integrais ajudaria a garantir não só a entrada, mas a permanência do aluno na sala de aula.

É importante lembrar que as casas dos estudantes mantidas pelo governo como condições para o acesso à universidade, representa uma via pela qual essa dar possibilidade de garantir a concretização dos estudos. No entanto, é necessário que, na discussão sobre a assistência estudantil como parte das políticas públicas, possam pensar não apenas nas casas estudantis, mas dar prosseguimento às bolsas que é um auxílio financeiro que tem por finalidade minimizar as desigualdades sociais e contribuir para a permanência e a diplomação dos estudantes de graduação em situação de vulnerabilidade socioeconômica. Além de expectativas e ideais, muitos estudantes, chegam à universidade com dúvidas e apreensões sobre as dificuldades que poderão enfrentar para se manter no ensino superior, muitas vezes longe de casa, sem recursos para pagar passagens de ônibus, alimentação, aluguel e livros. Portanto, é de fundamental importância as bolsas oferecidas pelo governo ou pelas próprias instituições, a fim de que os alunos tenham condições financeiras para ingressar e permanecer em seus cursos desejados.

Segundo Bourdieu e Champagne (1998, p. 221), a história de cada sujeito é singular e se constitui de trajetórias peculiares, mas algumas das trajetórias chegam a surpreender pela forma como sujeitos sociais desprovidos de capital cultural, econômico e social, "votados a um fracasso escolar praticamente certo", conseguem driblar o efeito de destino de seus vereditos e alcançar sucesso e longevidade escolar. No entanto, por mais que a entrada na universidade indique longevidade escolar, não é uma garantia de sucesso. A permanência do estudante das camadas populares na universidade é difícil e marcada por uma série de ajustes e ações práticas empreendidas por ele e por sua família em resposta aos diferentes obstáculos que vão surgindo ao longo do percurso. Em grande medida, são essas ações práticas, entendidas aqui como estratégias de sobrevivência na universidade, que garantirão ao estudante transpor a barreira universitária (PORTES, 1993, 2001). 
Diante da escassez de recursos da família, as estratégias e práticas mais comumente estabelecidas para garantir a "sobrevivência" na faculdade é buscar ajuda de material nas bibliotecas das instituições em que eles estão inseridos, e o trabalho que sem dúvida, repercute de forma distinta sobre os seus resultados escolares e sobre a sua vida acadêmica. Aqueles envolvidos em atividades que lhe consomem grande parte do tempo e que não mantêm qualquer ligação com a área de estudos, enfrentam enormes dificuldades em conciliar os estudos com o trabalho.

Sabe-se que ao ingressar na universidade, o estudante depara-se com situações pouco comuns a sua realidade. A partir disso, é necessária uma adequação, por parte do aluno, ao novo ambiente.

No ensino superior, os bons resultados do ensino e da aprendizagem vão depender em muito do empenho pessoal do aluno no cumprimento das atividades acadêmicas, aproveitando bem os subsídios trazidos seja pela intervenção dos professores, seja pela disponibilidade de recursos pedagógicos fornecidos pela instituição de ensino (SEVERINO 2007, p. 37).

Teixeira (2010) menciona que o ato ou hábito de estudar está diretamente ligado às competências transversais do ofício do aluno, diz que o estudante precisa desenvolver três atos acadêmicos: os hábitos de estudar, ler e escrever textos para tornar-se atuante na sociedade. Isso servirá como requisito para que o educando fique ligado ao fato de aprender por meio de boas práticas de leitura e atenção às aulas, e tenha a possibilidade de participar, interpretar e envolver-se no desenvolvimento de tais práticas. O conhecimento é importantíssimo para todos os segmentos da humanidade, tornou-se valioso, pois quem o domina pode ter acesso a inúmeras oportunidades. Tendo assim o trabalho como meio de desenvolvimento e aprendizagem para os jovens estudantes.

Demo (1998) diz que a Universidade poderia confirmar papel imprescindível e gerador frente ao desenvolvimento humano, desde que fizesse o signo exemplar da formação da competência, indicando 
a gestação do cidadão capaz de intervir eticamente na sociedade e na economia, tendo como alavanca instrumental o conhecimento inovador. Lembrando que a "educação e o conhecimento" são eixo da transformação produtiva.

O conhecimento é produto das relações dos seres humanos entre si e com o mundo. Nestas relações homens e mulheres são desafiados a encontrar soluções para situações para as quais é preciso dar respostas adequadas. Para isso, precisa reconhecer a situação, compreendê-la, imaginar formas alternativas de responder e selecionar a resposta mais adequada (FREIRE, 1981, p. 60).

A universidade representa a busca por uma vida melhor, o que, por sua vez, significa uma inserção no mercado de trabalho que possibilite um maior poder aquisitivo. Essa representação da universidade condiz com o seu novo papel, segundo Chauí (2001), ou seja, o adestramento para a mão de obra. Isso é vivido pelos universitários como a realização de um futuro que está sendo construído durante o curso universitário. Almeida (2004, p. 58), em uma pesquisa com estudantes da Universidade Estadual Paulista "Júlio de Mesquita Filho" (UNESP) sobre as representações dos universitários quanto aos ideais da juventude, encontrou a "preparação da vida profissional" como uma das principais aspirações que os estudantes podem adquirir para dar continuidade em sua vida estudantil e na sociedade.

Segundo Duarte Júnior (1996, p. 37), “atribuição de valores ao homem, é uma resposta à questão do significado das coisas para sua vida. Portanto, a razão humana é uma operação posterior à valorização". Com base nestas ideias, educar, além de colocar o indivíduo em contato com os sentidos que circulam em sua cultura, dá oportunidades, para que ele possa nortear sua vida. Sabendo que os valores humanos surgem das atividades do grupo social e transformam mecanismos elementares num esquema interpretativo de significação que se dá por meio dos símbolos criados pelo homem que interpreta o mundo e facilita a sua sobrevivência. 
O recorrente tema da democratização do acesso à educação superior no Brasil, em particular, no caso do ensino público, ganhou notável alento nos anos recentes. Em parte, isso decorre de transformações que extrapolam a sociedade brasileira, mas, certamente, as questões internas do país desempenharam papel mais relevante para a ênfase que caracterizou a retomada deste debate. Observa-se que os mecanismos de globalização das relações econômicas acentuaram nas mais diferentes sociedades o importante papel da educação superior, o que ocorreu concomitantemente com a perda da hegemonia das universidades na produção do conhecimento.

Santos (1996) menciona, com pertinência, a crise de legitimidade do meio acadêmico, decorrente, entre outros fatores, do confronto entre os saberes erudito e popular. Vale lembrar que é quase um consenso na sociedade que o acesso ao ensino superior tende a melhorar as possibilidades de ascensão social do indivíduo, ampliando sua capacidade de receber mais renda e, por isso, deveria constar no planejamento estratégico de qualquer governo interessado no desenvolvimento da sociedade.

Vale ressaltar que o direito à educação e a igualdade de acesso e permanência na escola estão expostos, respectivamente, nos artigos 205 e 206 da Constituição Federal de 1988. É preciso entender a educação e a assistência estudantil como um direito social e fazer com que a assistência seja, não apenas uma ajuda financeira, mas que articulada ao ensino, à pesquisa e à extensão e promovam a transformação dos assistidos. E eles possam dar sustentação a sua carreira estudantil, submetendo a divisão do tempo aos estudos e ao trabalho.

\section{A democratização e a estrutura social dos estudantes na universidade}

Para Bourdieu (2008), a escola é um espaço de reprodução de estruturas sociais e de transferência de capitais de uma geração para outra. É nela que o legado econômico da família transforma-se em capital cultural que, segundo o sociólogo, está diretamente relacionado 
ao desempenho dos alunos na sala de aula. Os próprios estudantes de baixa renda, acabam encarando a trajetória dos bem-sucedidos como resultante de um esforço recompensado. Um dos mecanismos de perpetuação da desigualdade está no fato, facilmente verificável, de que a frustração com o fracasso escolar leva muitos alunos e suas famílias a investir menos esforços no aprendizado formal.

Apesar das desvantagens educacionais de todo tipo, um número maior de estudantes de origem popular têm conseguido resultados que garantem vagas em diversos cursos em universidade de todo o Brasil (TEIXEIRA, 2011). Os resultados escolares de quem vive em certas condições são explicados pelo senso-comum como força de vontade (UHLE, 1997). Colocado deste modo, a escola e a sociedade se desincumbem da responsabilidade que tem com a educação e responsabiliza cada um por seu próprio sucesso ou fracasso.

É importante instrumentalizar os educandos com as atribuições básicas de investigar, identificar e interpretar os fatos relacionados à vida social para que eles sejam capazes de acompanhar a postura do mundo moderno e inserir-se ao meio como elemento ativo e participativo (DUARTE JÚNIOR, 1996). É preciso também, buscar no universo da educação a possibilidade de comunicar uns com os outros as suas reflexões para assim encontrarem abertura nas instituições e estas dar lhes mais oportunidades para que sintam gosto e satisfação pelos seus estudos, podendo lutar pela obtenção de recursos educacionais e melhores condições e oportunidades durante a vida universitária.

Freire (1981) revela que a visão do conhecimento na educação repercute na prática pedagógica e os seres humanos podem ser desafiados, mas encontram soluções para as indagações da sociedade, basta ele reconhecer a situação que depara no cotidiano. Para tal desenvolvimento será necessário que os educandos recebam orientações a fim de compreender e avaliar o impacto desse conjunto de transformações nas suas próprias vidas.

A concorrência por vaga nos cursos de maior prestígio social é acentuada tanto nas instituições públicas como nas privadas. Esse 
prestígio social prende-se, por sua vez, à hierarquia das ocupações, ou seja, à estratificação social. Conforme estudos de Ribeiro e Klein (1982), a escolha das carreiras é decorrente do condicionamento social da educação, que contribui decisivamente para o encaminhamento e distribuição dos candidatos pelos diversos cursos superiores. Nessa linha de pensamento, Collins (1971) ressaltou que a educação não se preocupa apenas com a transmissão do saber sistematizado. Subjacente a esse saber, ela impõe determinada cultura e ideologia. Dessa forma, contribui para manutenção e reprodução social, a fim de preservar e aumentar poderes e privilégios no interior da sociedade.

[...] a escola pode melhor do que nunca e, em todo caso, pela única maneira concebível numa sociedade que proclama ideologias democráticas, contribuir para a reprodução da ordem estabelecida, já que ela consegue dissimular a função que desempenha (BOURDIEU; PASSERON, 1992, p. 175).

Conforme Brasil (1998), a escola, inserida num contexto em que pode formar cidadãos autônomos e conscientes, tem o papel de ajudar o aluno se posicionar, representar sua capacidade de produção simbólica nas múltiplas linguagens, o que é essencial para se apropriarem das informações do atual contexto, permitindo que esses educandos tenham uma postura critica diante das informações recebidas. Nessa perspectiva, será importante que as universidades tenham condições e capacidade para construir uma sociedade que leva transformações aos indivíduos, pois a todo o momento estes estudantes são levados a enfrentar novos desafios, que exige uma visão mais crítica e abrangente. E, para que o jovem estudante universitário possa alcançar um potencial de conhecimento equilibrado, será necessário, descoberta de novas fronteiras e habilidades que lhe permita dominar as transformações do meio que o cerca possibilitando construir um novo mundo.

Os problemas sociais são os palcos de objetivos antagônicos das diferentes classes e grupos sociais. Cada classe considera e interpreta o passado e o presente, as relações de produções e as 
instituições políticas e os conflitos sócio-econômicos e as crises culturais em função de sua experiência, de sua vivência, de sua situação social, de seus interesses, aspirações, temores e desejos. O conhecimento da verdade pode ter conseqüências profundas diretas ou indiretas sobre o comportamento das classes sociais, sobre a sua relação de força, e, portanto, sobre o resultado de seus confrontos (LOWY, 2000, p. 202).

Em meio a toda problemática educacional, é importante enfatizar o tema democratização do ensino com equidade e qualidade que é de suma importância e complexidade. Mas a experiência que o Brasil está vivenciando no âmbito da educação superior é muito rica e serve como referência para vários estudos na sociedade contemporânea, a exemplo do Programa Nacional de Bolsa Permanência (PBP) para estudantes de graduação de universidades e institutos federais. Este programa será destinado tanto a alunos que possuem renda familiar média, como também aos quilombolas e indígenas, com um investimento que será complementar ao Plano Nacional de Assistência Estudantil (PNAES). Vale lembrar que é resgate da cidadania, da plenitude dos direitos sociais, da participação social e política dos indivíduos (cidadãos) em todos os aspectos da sociedade. Isto é, o exercício da cidadania pela participação social, política e cultural, além do acesso aos direitos básicos.

É importante também a efetivação de uma política pública voltada para o ensino superior e garantir o acesso e permanência do aluno, a equidade de oportunidades e a efetivação da democratização do espaço escolar. Diante destas afirmações, observa-se que precisa amadurecer o investimento para realmente realizar a democratização pretendida, contudo, não se podem negar os efeitos positivos do programa na vida dos estudantes beneficiados. Ao possibilitar a permanência no ensino superior, dá oportunidade muitos estudantes de baixa renda de poderem mudar sua realidade, oportunizando ter uma profissão, melhorando sua renda, e resgatando sua cidadania. Nesse sentido é preciso que o governo federal continue buscando o aprimoramento contemplando mudanças na política de permanência do estudante universitário. 


\section{Referências}

ALMEIDA, L. L. A juventude e suas representações. Revista da UFG: Ensino, Pesquisae Extensão, Goiânia, ano 4, n. 1, jun. 2004.

BOURDIEU, Pierre; CHAMPAGNE, Patrick. Os excluídos do interior. In: NOGUEIRA, Maria Alice; CATANI, Afrânio. Escritos de Educação. Petrópolis: Vozes, 1998. p. 217-227.

; CATANI, Afrânio M.; NOGUEIRA, Maria Alice (Org.). Escritos de educação. 10. ed. Petrópolis: Vozes, 2008.

; PASSERON, J. C. A reprodução: elementos para uma teoria do sistema de ensino. Rio de Janeiro: Francisco Alves, 1992.

BRANDÃO, Zaia; MENDONÇA, Ana Waleska (Org.). Por que não lemos Anísio Teixeira? Uma tradição esquecida. Rio de Janeiro: Ravil, 1997. p. 27-46.

BRASIL. Ministério da Educação e do Desporto. Salto para o futuro: reflexão sobre a educação no próximo milênio: Secretaria de Educação a Distancia. Brasília: Ministério da Educação e do Desporto, SEED, 1998.

CHAUÍ, M. Escritos sobre a universidade. São Paulo: Ed. da UNESP, 2001.

COLLINS, R. Functional and conflet theories of educational stratification. American Sociological Review, v. 36, p. 1.002-1.019, dez. 1971.

DEMO, Pedro. Educarpela pesquisa. 4. ed. Campinas: Autores Associados, 1998.

DUARTE JUNIOR, João Francisco. Fundamento estético da educação. São Paulo: Cortez/Autores Associados, 1986.

FARIA FILHO, Luciano Mendes. Instrução elementar no século XIX. In: LOPES, Eliane Marta Teixeira; FARIA FILHO, Luciano Mendes de; VEIGA, Cynthia Greive (Org.). 500 anos de educação no Brasil. Belo Horizonte: Autêntica, 2000. p. 135-149.

FREIRE, Paulo. Pedagogia do oprimido. 9 ed. Rio de Janeiro: Paz e Terra, 1981. 
GOUVEIA, A. J. Democratização do ensino superior. Revista Brasileira de Estudos Pedagógicos, Rio de Janeiro, v. 50, n. 112, p. 232-245, out./dez. 1968.

LOWY, Michael. As aventuras de Karl Marx contra a Barão de Munchhausen: marxismo e positivismo na sociologia do conhecimento. 7. ed. São Paulo: Cortez, 2000.

MOEHLECKE, Sabrina. Fronteiras da igualdade no ensino superior: excelência e justiça racial. 2004. Tese (Doutorado em Educação) - Faculdade de Educação, Universidade de São Paulo, São Paulo, 2004.

MORCHE, Bruno; NEVES, C. B. Políticas de inclusão social na educação superior brasileira: as políticas afirmativas e o ProUni. In: ALAS, 28., 2011. Anais... Recife: ALAS, 2011. GT25: Educação e desigualdade social. Disponível em: < http:/ / www.alas2011 recife.com/>. Acesso em: 28 nov. 2011.

PORTES, Écio Antonio. Trajetórias e estratégias do universitário das camadas populares. 1993. 267 f. Dissertação (Mestrado em Educação) - Universidade Federal de Minas Gerais, Belo Horizonte, 1993.

.Trajetórias escolares e vida acadêmica do estudante pobre na UFMG: um estudo a partir de cinco casos. 2001.267 f. Tese (Doutorado em Educação) - Universidade Federal de Minas Gerais, Belo Horizonte, 2001.

RIBEIRO, S.; KLEIN, R. A divisão interna da universidade: posição social das carreiras. Educação e Seleção, São Paulo: Fundação Carlos Chagas, n. 5, p. 29-36, jan./jul. 1982.

SANTOS, B. S. Pela mão de Alice: o social e o político na pós-modernidade. São Paulo: Cortez, 1996.

SANTOS, N. L. L. Aceleração da aprendizagem. In: SILVA, E. B. (Org.). A educaşão básica pós-LDB. São Paulo: Pioneira, 1998. p. 61-73.

SEVERINO, Antônio Joaquim. Metodologia do trabalho científico. 23. ed. rev. e atual. São Paulo: Cortez, 2007. 
TEIXEIRA, B. A. M. Freitas. Entrei na universidade: e agora, o que faço para tornar-me um estudante universitário? In: ALAS, 28., 2011, Recife. Anais eletrônicos... Recife: ALAS, 2011. GT25: Educação e desigualdade social. Disponível em: <https://www.ufpe.br/agencia/clipping/index. php?option $=$ com_content\&view $=$ article\&id $=7393$ :apos-entrar-a-lutapara-se-manter-na-universidade\&catid $=72 \&$ Itemid=122>. Acesso em: 28 nov. 2011.

TEIXEIRA, Elizabeth. As três metodologias: acadêmica, da ciência e dapesquisa. 7. ed. Petrópolis: Vozes, 2011.

UHLE, A. B. Bittencourt. Reflexões sobre a filosofia e a cozinha. Cadernos CEDES,Campinas, v. 18, n. 42, ago. 1997. Disponível em: <http://www.scielo.br/scielo.php?>. Acesso em: 28 nov. 2011. 